\title{
INTERSTITIAL CELLULAR AND MATRIX RESTORATION OF CARDIAC VALVES AFTER CRYOPRESERVATION
}

Robert H. Messier, Jr, MD, PhD

Barbara L. Bass, MD

Patrick W. Domkowski, MD, PhD

Richard A. Hopkins, MD
Objectives: We previously characterized the porcine aortic leaflet interstitial cell phenotype as having both synthetic and contractile characteristics; that is, it is a myofibroblast. In this study we hypothesized (1) that the cryopreservation of aortic valves causes a significant reduction in cell density, (2) that it simultaneously causes alterations in representative components of extracellular matrix, and (3) that both of these processes are reversible. Methods: Seventy-two leaflets from 24 porcine aortic valves were studied. Whole valves were subjected to variable lengths of preharvest ischemia (group 1), ischemia followed by processing analogous to clinical methods (group 2), and ischemia followed processing with an organ culture type of resuscitation (group 3). Vital dye exclusion by cells enzymatically dispersed from leaflets was used to quantify viability. Electron and light microscopy, immunohistochemical assay, and a silicone rubber substratum contractility assay were used both in dispersed cell preparations and in leaflet cross sections to examine structural, ultrastructural, and functional changes across the 3 groups through a range of preharvest ischemic times. Results: Results indicated that harvest ischemic periods between 2 and 24 hours after donor death were not responsible for cell number reductions. During this interval overt dissolution of chondroitin sulfate simultaneous with a relative sparing of fibronectin was evidenced by immunohistochemical staining. Although not reduced in number, ischemic interstitial cells did show significant ultrastructural evidence of injury and suppressed monoclonal binding to vimentin and $\alpha$-smooth muscle actin. After cryopreservation, viable cell numbers were always markedly reduced at all ischemic intervals and damage to both soluble extracellular matrix components and cell ultrastructure was increased. At all time and processing points, however, some retention of matrix secretory and cellular contractile capabilities was observed among the surviving cells. After the extended periods of preharvest ischemia (2-24 hours) followed by processing, a restitution of functioning cells was accomplished by means of whole-leaflet incubation in $15 \%$ fetal bovine serum. Conclusions: After application of the described methods, new cells within restored intact leaflets as well as in single-cell preparations demonstrated normal ultrastructure and contractile and synthetic functions (normal phenotypic expression). If functioning leaflet interstitial cells can contribute to homograft durability, bioengineering methods for pretransplantation cell repopulation could be refined with these techniques and applied to clinical valve transplantation. (J Thorac Cardiovasc Surg 1999; 118:36-49)
From The Departments of Surgery of the Washington, DC, Veterans Affairs Medical Center, Georgetown University Medical Center, Washington, DC, Brown University, Providence, RI, and The Collis Cardiac Surgical Research Laboratory of the Lifespan Academic Medical Center, Providence, RI.

Supported in part by research grants from The American Heart Association and Lifenet.
Received for publication June 26, 1998; revisions requested Sept 13, 1998; revisions received Nov 24, 1998; accepted for publication March 2, 1999.

Address for reprints: Richard A. Hopkins, MD, Chief, Cardiothoracic Surgery, Brown University School of Medicine, The Miriam Hospital, 164 Summit Ave, Providence, RI 02906.

$12 / 1 / 98429$ 
T he cryopreserved semilunar valve is a useful prosthesis for numerous applications in reconstructive cardiac surgery, especially in the pediatric right ventricular outflow tract. ${ }^{1}$ It has been suggested that the cells residing within the cusp matrix interstitium are important to posttransplantation durability, theoretically because of retained interstitial cellular functions (matrix refurbishing and cuspal remodeling). ${ }^{2-5}$ Conversely, others have reasoned that any significance of this cell viability may be more as a marker of "gentle" valve preservation. ${ }^{6}$ Both intuition and a number of clinical studies suggest that gentle treatment of donor leaflet interstitial cells has improved durability, and cryogenic preimplantaton protocols have therefore been designed specifically with the intent of maintaining postthaw viability of matrix cells (but not endothelial cells). ${ }^{7}$ Importantly, no long-term studies in either human beings or animals have been published that show a posttransplantation proliferation of donor leaflet cells to suggest that in vivo resuscitation of the cell population can or does occur.

We previously developed a model of valve harvest and cryogenic storage that closely resembles clinical practice, and with it we evaluated leaflet interstitial cellular metabolism with respect to fluxes in adenine nucleotides. ${ }^{8-12}$ These studies showed a graduated nucleotide depletion in leaflet cells. We additionally characterized a porcine aortic leaflet myofibroblast cell line. ${ }^{13}$ In previous studies we correlated the apparent damage reflected by reductions in the components of the adenine nucleotide pool in cryopreserved aortic valves (both porcine ${ }^{8}$ and human ${ }^{14}$ ) with reductions in leaflet cell densities and altered functional (synthetic) and ultrastructural features consistent with reversible and irreversible cell injury. Because cryopreservationassociated injury has been reported to be reversible in other eukaryotic systems, ${ }^{15}$ this study examined whether a modified organ culture technique could restore leaflet cell population and function. We tested our hypothesis that the retention of even a small residual population of viable cells would allow proliferation to restore constitutive cell density and cell function in both single-cell suspensions and intact leaflets.

\section{Materials and methods}

Experimental design. The preparation of human valves for use as allograft prostheses consists of several processing phases that take place before insertion. These include a variable preharvest ischemic period (limited to 24 hours in the United States), during which the tissue remains unperfused in situ as the donor cools. ${ }^{7}$ We suspect that harvesting, transport, and processing may result in leaflets with substantially injured interstitial cells. ${ }^{12}$ For this study 3 experimental groups were designed to examine variable preharvest ischemia, variable preharvest ischemia followed by completed processing (disinfection, cryopreservation, storage, and thawing), and variable preharvest ischemia and processing followed by an organ culture period of valve "resuscitation."

Valve harvest protocol. Mediastinal contents including the heart, great arteries (aorta to ligamentum arteriosum), thymus, and portions of the pericardium were cleanly procured from 24 female 8-month-old Yorkshire swine at a local abattoir. Each was obtained within 40 minutes after electrical stunning followed by exsanguination, with the myocardium usually fibrillating at the time of recovery. At retrieval the specimens were allocated into sets of 6 to sustain varying periods of ischemia $(2,6,12$, or 24 hours, including the 40 minutes in situ), during which the tissue was maintained in sterile organ procurement bags (Steri-Drape Isolation Bag; $3 \mathrm{M}$ Health Care, St Paul, Minn) at room temperature. These intervals were arbitrarily selected to simulate conditions in a cooling cadaver with variable times until actual organ harvest. At the end of $2,6,12$, or 24 hours, the aortic roots were disarticulated from the hearts, the conduits were rinsed in sterile phosphate-buffered saline solution (PBS; Life Technologies, Inc, Rockville, Md), and leaflets were prepared as previously described. ${ }^{16}$

Group allocation. To control for variability among the animals each separate leaflet of the 3 from every valve was assigned to assay at 1 of the 3 experimental intervals: group 1 , ischemia only; group 2, ischemia plus disinfection plus cryopreservation plus thaw; and group 3, ischemia plus disinfection plus cryopreservation plus thaw plus resuscitation. At the conclusion of the designated 2-, 6-, 12-, or 24-hour ischemic period the group 1 leaflets were removed $(n=6$ leaflets/ischemic period, 1 from each of the 24 valves). All valves (now bicuspid minus the group 1 leaflets) were then rinsed in sterile PBS and immersed in a $4{ }^{\circ} \mathrm{C}$ solution of antibiotics reconstituted in Roswell Park Memorial Institute medium 1640 (Life Technologies): $240 \mu \mathrm{g} / \mathrm{mL}$ cefoxitin, 120 $\mu \mathrm{g} / \mathrm{mL}$ lincomycin, $100 \mu \mathrm{g} / \mathrm{mL}$ polymyxin $\mathrm{B}$, and $50 \mu \mathrm{g} / \mathrm{mL}$ vancomycin. ${ }^{7}$

After 24 hours of this cold disinfection the valves were rinsed again in sterile PBS and cryopreserved. ${ }^{17}$ The 24-hour group 2 leaflets (ischemic for 2, 6, 12, or 24 hours, disinfected, and cryopreserved) were then thawed, excised from their anuli, and assayed. Simultaneously, each group 3 leaflet was excised from its anulus and placed into a $35-\mathrm{mm}^{2}$ culture well containing M199 medium (Life Technologies) supplemented with $15 \%$ heat-inactivated fetal bovine serum (FBS; Life Technologies). We previously showed that this concentration of FBS is strongly mitogenic to porcine aortic leaflet interstitial cells. ${ }^{12,13}$ These "restoring" valves were incubated in a humidified atmosphere of $95 \%$ air and 5\% carbon dioxide at $37^{\circ} \mathrm{C}$ for 8 days and then assayed.

\section{Viability, proliferation, and contraction}

Preparation of dispersed cells. At the time of assay for each leaflet in each of the 3 groups and at all 4 ischemic points the central third of each cusp (beginning at the nodule of Arantius and ending at a point 3 to $5 \mathrm{~mm}$ from the base) 
was excised longitudinally from the base. All 72 leaflets from the 24 valves ( $n=6$ valves/ischemic period, 4 ischemic periods/group) were used in the viability assessments. The excised segments were removed, dried, weighed on a Mettler balance (Mettler-Toledo International, Inc, Greifensee, Switzerland), rinsed in chilled PBS, and placed into M199 medium with $15 \%$ heat-inactivated FBS and $0.08 \%$ collagenase (lyophilized, prepared from Clostridium histolyticum; Life Technologies). Antibiotics (100 U/mL penicillin G, 100 $\mu \mathrm{g} / \mathrm{mL}$ streptomycin, and $5 \mu \mathrm{g} / \mathrm{mL}$ amphotericin B) were added to each tube and each tube was incubated in a humidified atmosphere of $95 \%$ air and $5 \%$ carbon dioxide at $37^{\circ} \mathrm{C}$.

Viability. After 24 hours in collagenase suspensions were centrifuged twice for 2 minutes at $25 \mathrm{~g}$ with an intervening wash in sterile PBS. Cells were resuspended in M199 medium and the aliquots from each suspension were counted by hemocytometer, with Trypan blue dye exclusion to determine viability. Counts were performed by 2 separate investigators blinded to the group identity of the leaflet and were normalized as cells per milligram of wet weight of leaflet segment.

Proliferation. We assessed changes in the ability of aortic leaflet interstitial cells to proliferate after ischemia and completed processing with cells dispersed from the 2-and 24-hour group 1 and 2 leaflets, anticipating that any decreases (or increases) in proliferation potential would be demonstrable at the ischemic extremes. After deriving the viability counts for each experimental interval at each ischemic time, aliquots from the digestates of the 2- and 24-hour group 1 and 2 leaflets were separately resuspended in M199 medium supplemented with $15 \%$ FBS. These were then counted by hemocytometer and plated in quadruplicate on plastic, 24-well, 2$\mathrm{cm}^{2}$ surface area plates (Multiwell; Becton Dickinson and Company, Franklin Lakes, NJ) at a density of $2 \times 10^{4}$ cells/well. After a 24-hour period of recovery in M199 medium supplemented with $15 \%$ FBS, the cultures were deprived of serum for 24 hours and 4 random wells per plate were counted with a Coulter counter (Coulter Corporation, Hialeah, Fla). These numbers were averaged to establish baseline counts for growth curves. The remaining wells had M199 medium supplemented with 15\% FBS administered and growth curves were derived from harvest $(0.25 \%$ trypsin-ethylenediaminetetraacetic acid) and quantitation at 24, 48, 72, and 96 hours after serum administration. Trypsin-digested cells were examined under the light microscope before counting to ensure that single cells, rather than multicellular aggregates, were present. Accuracy of quantitation was verified through periodic visual counting with a hemocytometer.

Cellular contractility. To verify that the ability of leaflet interstitial cells to contract is maintained throughout ischemia, processing, and resuscitation, we employed the method of Harris and colleagues. ${ }^{17,18}$ The preparations were stimulated with $10^{-7} \mathrm{~mol} / \mathrm{L}$ L-epinephrine, $3.2 \times 10^{-7} \mathrm{~mol} / \mathrm{L}$ bradykinin, $3.2 \times 10^{-7} \mathrm{~mol} / \mathrm{L}$ angiotensin II, $110 \mu \mathrm{mol} / \mathrm{L}$ carbachol, and $110 \mu \mathrm{mol} / \mathrm{L}$ isoproterenol (INN: isoprenaline sulphate). ${ }^{12,13}$ For each administration, 10 to 50 cells were observed continuously for 40 minutes. Photographs were taken under the phase-contrast microscope (Nikon Inc,
Melville, NY) before and immediately after each compound was applied and at the time of response.

\section{Cellular and matrix protein}

Preparation of leaflets and immunohistochemical examination. For the whole-leaflet preparations, 4 leaflet portions were washed several times in PBS (with calcium and magnesium ion, hereafter $P B S++$ ) fixed in $4 \%$ buffered paraformaldehyde, and processed for paraffin embedding. The embedded tissue was then sectioned to between 4 and $5 \mu \mathrm{m}$ in thickness, mounted on standard glass microscope slides, and maintained in a $4{ }^{\circ} \mathrm{C}$ refrigerator until use. The slides had the paraffin removed in PBS++ and were incubated for 20 minutes in a blocking serum (5\% goat serum and $1 \%$ bovine serum albumin in PBS). After washing in PBS (without calcium and magnesium ion, hereafter $P B S-$ ) the sections were placed in a humidified $5 \%$ carbon dioxide incubator at $37^{\circ} \mathrm{C}$ for 60 minutes and each was administered 1 of the primary antibodies in PBS- (supplemented with $1 \%$ bovine serum albumin) for 2 hours. After washing the secondary antibodies (antimouse immunoglobulin G-fluorescein isothiocyanate conjugate; Sigma, St Louis, Mo) were then applied at 1:100 dilution and cells were subsequently incubated for $45 \mathrm{~min}$ utes at $37^{\circ} \mathrm{C}$ in a humidified $5 \%$ carbon dioxide incubator. After washing the slides were mounted with Fluoromount $\mathrm{G}$ (Fisher). Sections were examined with an epifluorescence microscope (Nikon Diaphot) equipped with a blue filter and photographed (TMAX 3200; Eastman Kodak Company, Rochester, NY). As control preparations several sections were incubated in PBS - with secondary antibody (no primary antibody) to detect any fluorescence resulting from nonspecific binding of secondary antibody. In addition, sections were viewed in the absence of either primary or secondary antibody to demonstrate any autofluorescence.

Antisera. The following primary antibodies were used at empirically derived dilutions: (1) 1:28 monoclonal anti- $\alpha$ smooth muscle actin (A-2547; Sigma), (2) 1:100 monoclonal antivimentin (V-6630; Sigma), (3) 1:200 monoclonal anti-chondroitin sulfate (C-8035; Sigma), and (4) 1:100 monoclonal anti-cellular fibronectin (F-6140; Sigma). No nuclear counterstains were used. The antiserum to $\alpha$-smooth muscle actin has been extensively characterized as monospecific to smooth muscle cells. ${ }^{19}$ No cross-reaction with fibroblast or endothelial actin isomers (stress fibers) has been found.

Leaflet ultrastructure (preparation and electron microscopy). Five cusp segments from valves at the 2- and 24-hour ischemic time points of each group were used to qualitatively study ultrastructural and cellular effects of ischemia and processing, as well as to assess histologic status of the leaflets after resuscitation. The central third from each of the 5 cusps per interval was dissected and fixed in phosphate-buffered $2 \%$ paraformaldehyde and $1 \%$ glutaraldehyde solution $(\mathrm{pH}$ 7.4). Thin sections were washed in buffered sucrose solution $(0.1 \mathrm{~mol} / \mathrm{L}$ phosphate buffer, $5 \%$ sucrose solution) and postfixed at $4^{\circ} \mathrm{C}$ in phosphate-buffered $2 \%$ osmium tetroxide solution. Ultrathin longitudinal and cross sections from 2 selected areas of the semithick sections devoid of artifactual damage were mounted on 300-mesh 
copper grids ( 6 grids/area). These specimens were enhanced with uranyl acetate and lead citrate for 1 to 2 minutes $^{20}$ and viewed under the transmission electron microscope (Zeiss EM 10CA; Carl Zeiss, Inc, Thornwood, NY) at $80 \mathrm{kV}$. Photographs of densely populated ( $\geq 4$ cells/field) fields were then taken with electron microscopy film (Kodak ESTAR Thick Base 4489).

\section{Results}

\section{Cell viability and proliferation studies}

Group 1, ischemia only. Counts of live cells dispersed from the 72 leaflets (24 leaflets/group; 6 leaflets/ischemic time) are depicted in Fig 1. In group 1 a mean of $1.6 \pm 0.33 \times 10^{4}$ cells $/ \mathrm{mg}$ were able to exclude trypan blue after 2 hours of preharvest ischemia, and this number did not significantly change in 24 hours $(P=.99$ for 2 -hour group 1 leaflets versus 6-hour, 12-hour, and 24-hour group 1 leaflets). Although no discernible decrease in cells capable of trypan blue exclusion was noted in the 24-hour group 1 leaflets, histologic sections of the leaflets revealed diminished cellularity.

Group 2, after processing. After 24 hours in cold $\left(4^{\circ} \mathrm{C}\right)$ antibiotic solution followed by cryopreservation and thaw, viable counts were reduced to $0.23 \pm 0.04$ to $0.26 \pm 0.08 \times 10^{3}$ cells $/ \mathrm{mg}(P<.05$ versus all group 1 counts). Light microscopic sections of these fully processed leaflets consistently indicated fewer intact cells. In the 24-hour ischemia and processing set of group 2 leaflets nuclei appeared to be more pyknotic on light microscopy than did those in the 2-hour group 2 leaflets.

Group 3, resuscitation. Proliferative capabilities were assessed from leaflets sustaining 2 and 24 hours of preharvest ischemia to separate any alterations in mitotic potential among the cells surviving cryopreservation caused by increasing doses of preprocessing ischemia. Fig 2 depicts growth curves of cells obtained directly from leaflets at each ischemic interval and indicates that each group contained cells that retained the ability to proliferate in vitro in growth media supplemented with $15 \%$ FBS. Viable cell counts after resuscitation returned in cell population to levels equivalent to those obtained from the minimally ischemic unprocessed leaflets. Toluidine blue-stained sections from the restored leaflets showed cellularity similar to that noted in the briefly ischemic leaflets; nuclei were rounded with visible nucleoli and few pyknotic nuclei were observed. The time pattern of this repopulation, determined by vital dye exclusion counting of digested leaflets on each day of the resuscitation period, is depicted in the inset of Fig 2.

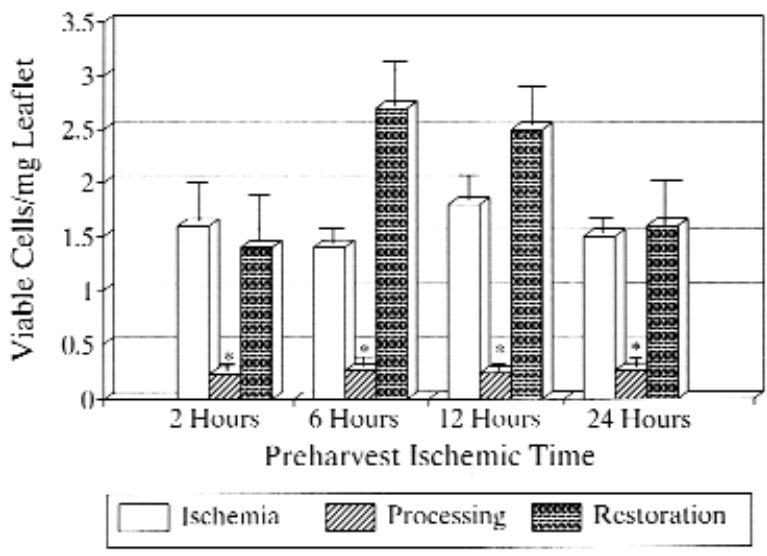

Fig 1. Vital dye exclusion. The $x$-axis indicates duration of preharvest ischemia endured by valves before allocation into 3 groups. Group 1 valves sustained ischemia only, group 2 valves sustained both ischemia and full processing (disinfection in antibiotics for 24 hours at $4^{\circ} \mathrm{C}$, cryopreservation, and thawing), and group 3 valves sustained ischemia, processing, and restoration. The y axis indicates viable cell counts in $10^{4}$ cells/mg leaflet for each type of leaflet. Twenty-four valves were collected and each leaflet was allocated to group 1, 2, or 3 ( $\mathrm{n}=24$ leaflets/group, 6 leaflets/ischemic time.) There were no significant differences in number of cells capable of trypan blue exclusion after different ischemic exposures. However, processing caused marked reductions in viable cells regardless of antecedent ischemia, and restoration returned cell numbers to baseline. Asterisk indicates $P=.05$ versus group 1 and group 3 by analysis of variance.

\section{Ultrastructure}

Ischemia (group 1). After 2 hours of ischemia the myofibroblasts in leaflet cross sections appeared uninjured on transmission electron microscopy. As previously characterized some cells looked predominantly contractile, with abundant intracellular myofilaments and periodically spaced electron-dense bodies. Others lacked these microfilament bundles and appeared to have a more synthetic cytoplasm. Intercellular junctions were frequently noted, including annular and straight gap junctions as well as complex desmosomal junctions. Similar to cells described by Bairati and DeBiasi, ${ }^{21}$ clusters of pure smooth muscle cells with complete basal laminae, subplasmalemmal plaques, intracellular myofilaments, and few intracellular organelles were noted.

After 24 hours of ischemia (24-hour group 1) only rare cells appeared completely uninjured. In many of the clearly injured cells the plasma membrane was largely intact but the nuclear membrane showed extensive separation of the inner and outer layers. Many 


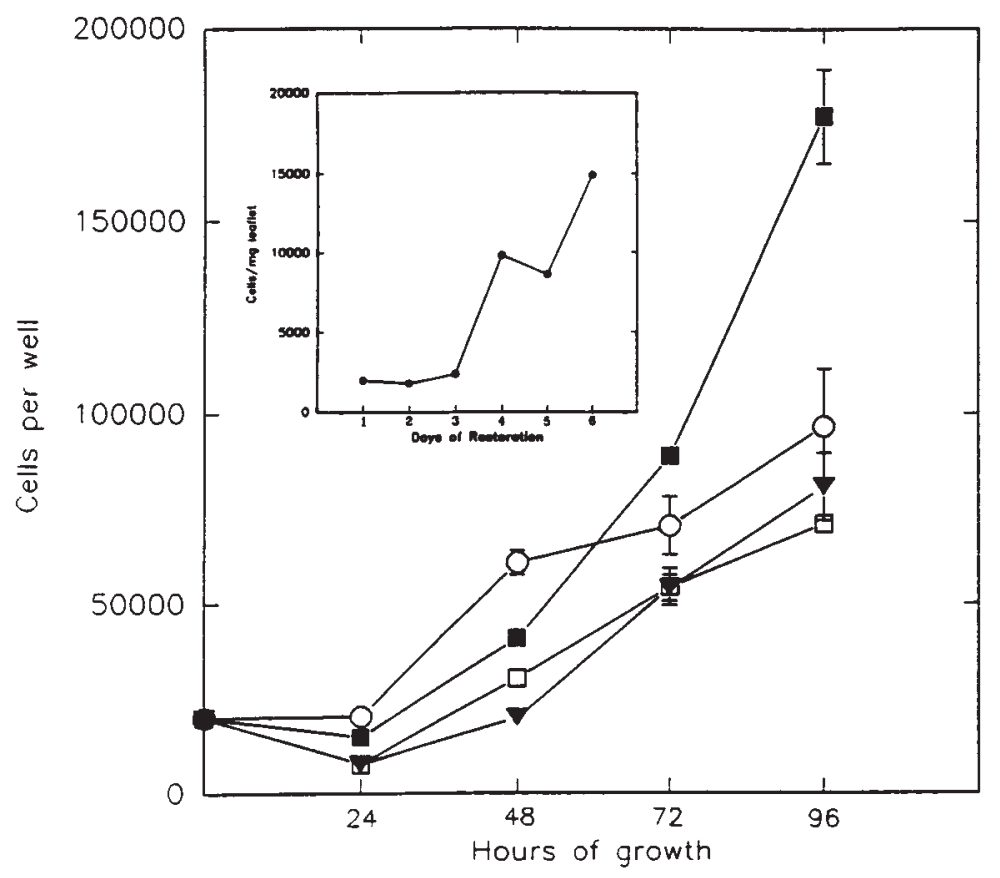

Fig 2. Growth curves and in situ repopulation (inset). Main graph depicts growth rates of cells released from leaflets at each interval (2 hours of preharvest ischemia only, 2-hour group 1, open circles; 24 hours of preharvest ischemia only, 24-hour group 1, filled squares; 2 hours of preharvest ischemia and full processing, 2-hour group 2, open squares; 24 hours of preharvest ischemia and full processing, 24-hour group 2, filled triangles). Regardless of ischemia or processing, aortic leaflet interstitial cells retain ability to respond mitogenically to medium supplemented with $15 \%$ FBS. This retained mitotic potential was used to bioengineer cellular restoration from residual population surviving processing. Inset depicts pattern of repopulation. On each of 6 days of restoration 1 leaflet was weighed and digested in $0.08 \%$ collagenase. After release of cells, viable numbers were determined by hemocytometer and trypan blue exclusion and plotted. These data suggest that rate of repopulation was similar to native growth rates in $15 \%$ FBS.

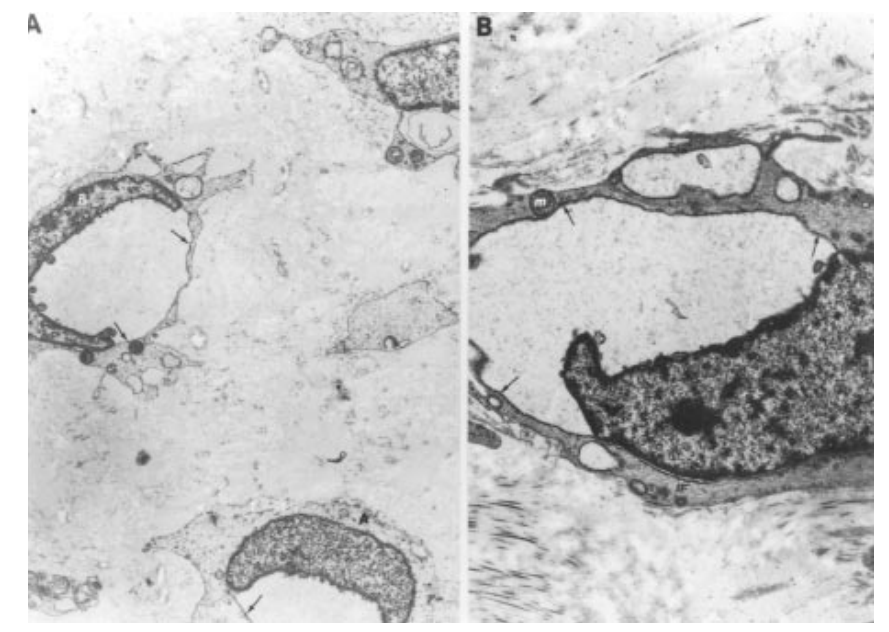

Fig 3. Transmission electron micrographs of leaflets after 24 hours of preharvest ischemia delineating extensive separation of outer and inner nuclear membrane (black arrows in both panels). Despite nuclear changes, some cells (white arrows, $\mathbf{A}$ ) have disrupted plasma membranes whereas others (B) are intact. IF, Intermediate filaments; $M$, mitochondria. (A, Uranyl acetate and lead citrate; original magnification $\times 11,610$. B, Uranyl acetate and lead citrate; original magnification $\times 14,490$.) 


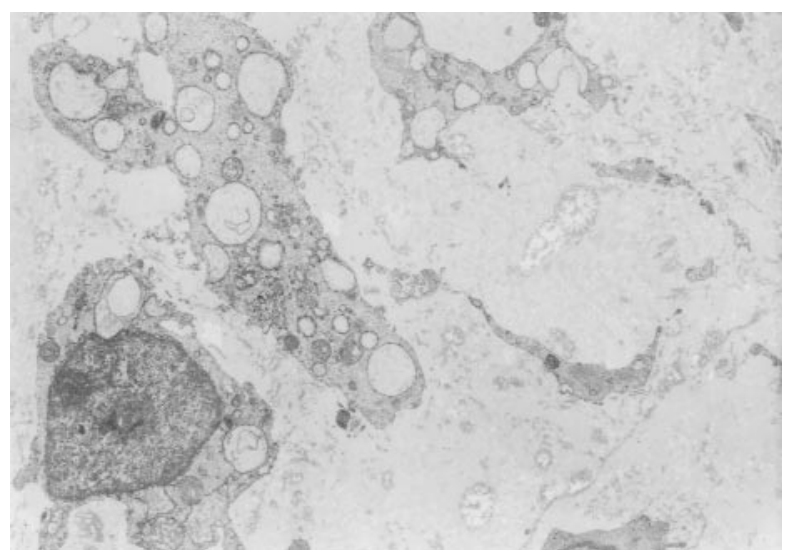

Fig 4. Transmission electron micrograph demonstrating extensive cellular injury in leaflets sustaining 24 hours of preharvest ischemia and completed processing (24-hour group 2). Clear areas (arrows) surrounding cells may represent matrix dissolution. (Uranyl acetate and lead citrate; original magnification $\times 9180$.)

nuclei that showed this feature assumed a crescent appearance (Fig 3).

Ischemia and processing (group 2). The injury after ischemia, disinfection, cryopreservation, and thaw (group 2) was severe. An increased number of necrotic cells was evident even in the 2-hour group 2 leaflets. In nearly every field, however, occasional cells could be found with plasma membranes that retained continuous lipid bilayer configurations and normal rounded euchromatic nuclei. Intracellular neutral lipid droplets and myelin figures were often observed in the cryopreserved leaflets. With an antecedent 24 hours of preharvest ischemia (24-hour group 2) the number of cells showing irreversible injury (necrosis, karyolysis, discontinuous plasma membranes, and mitochondrial dense bodies) was markedly increased from numbers in all previous groups. Most cells were surrounded by pericellular halos, consistent with a dissolution of soluble matrix components (Fig 4). Scattered cells with intact nuclei and plasma membranes continued to be occasionally represented, however, and synthetic and contractile phenotypes were not readily distinguishable.

Resuscitation (group 3). Cellular proliferation was evident in both group 3 valve sets ( 2 and 24 hours of preharvest ischemia), with repopulation by viable cells observed particularly in the lamina ventricularis (Fig 5). Various stages of mitosis and cytokinesis were noted (Fig 6). Cellular reorganization with reformed intercellular junctions could be appreciated (Fig 7). Scattered remnants of necrotic cells could be seen in the central portions of the leaflet segments.

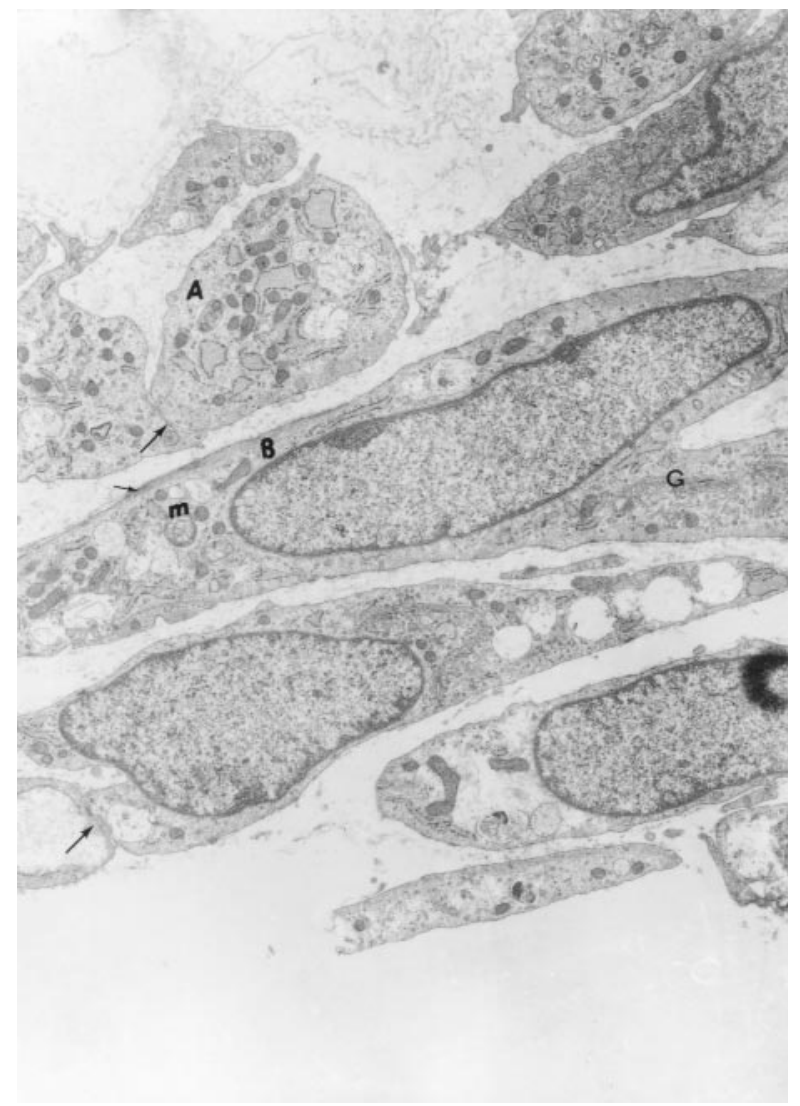

Fig 5. Transmission electron micrograph of leaflet resuscitated from 24 hours of preharvest ischemia followed by disinfection, cryopreservation, and thawing. Well-organized cellular architecture and some intercellular junctions (long arrows) are apparent. Adjacent to subplasmalemmal plaques (small arrow) is an incomplete basal lamina. Rudimentary myofilaments appear to be inserting at subplasmalemmal plaque. Portion of cell A possesses organelles, which continue to show moderate dilatation of the rough endoplasmic reticulum as well as electron-dense deposits within mitochondria. Intact intracellular organelles and myelin figure $(\mathrm{m})$ are appreciable in cell B. G, Golgi body. (Uranyl acetate and lead citrate; original magnification $\times 9180$.)

Cellular and matrix proteins. The intermediate filament vimentin was identifiable throughout all experimental intervals (Fig 8). In the 2-hour group 1 leaflets staining was indicative of a homogeneous distribution among the aortic leaflet interstitial cells occupying the entire interstitium. After 24 hours of preharvest ischemia (24-hour group 1) a reduced binding was evident in scattered regions of the matrix. This pattern of sparser staining was also observed in the 2-hour group 2 leaflets. With 24 hours of preharvest ischemia followed by completed processing, the intensity of binding was minimal. 

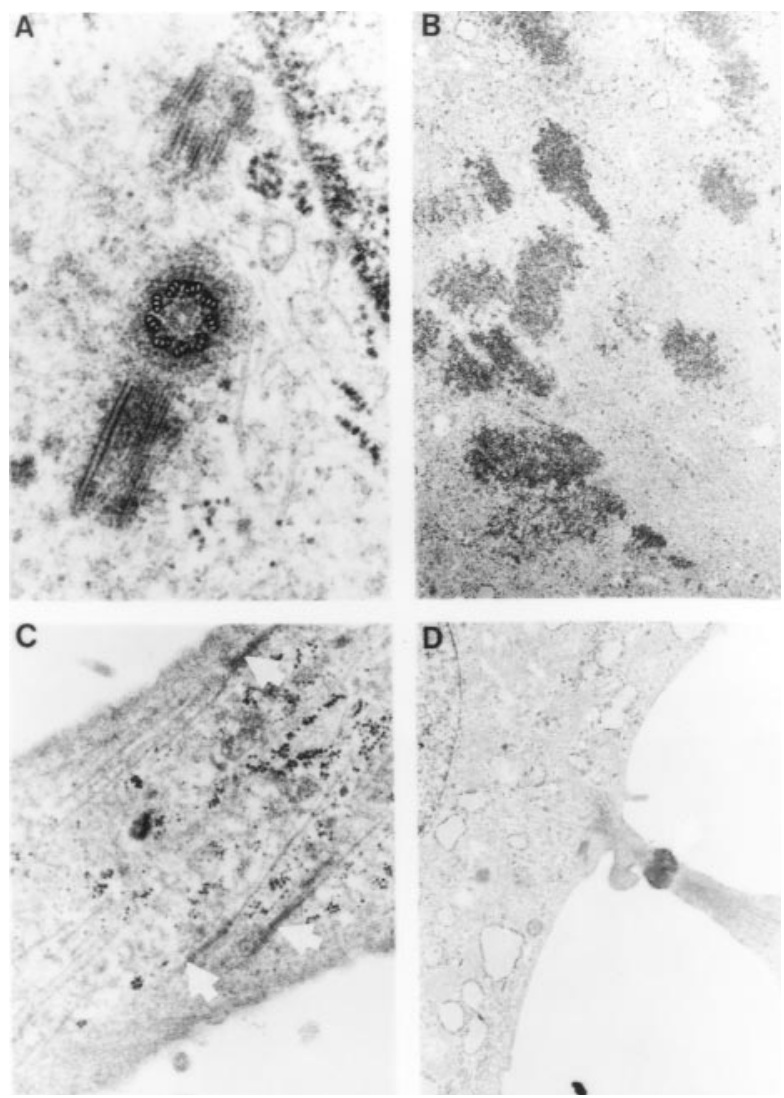

Fig 6. Composite transmission electron micrographs delineating key events of cellular mitosis and cytokinesis in 24hour resuscitated leaflet (24-hour group 3). A, Initial doubling of paranuclear centriole, early prophase. Fourth centriole is not in field. (Uranyl acetate and lead citrate; original magnification $\times 90,900$.) $\mathbf{B}$, Early metaphase rearrangement of chromosomes along equatorial plane. (Uranyl acetate and lead citrate; original magnification $\times 9180$.) $\mathbf{C}$, After onset of anaphase microtubules are organizing into stem bodies within this intercellular bridge. Note electron-dense matrix of stem bodies (arrows) containing tips of microtubules. (Uranyl acetate and lead citrate; original magnification $\times 28,800$.) $\mathbf{D}$, Complete midbody formation that represents fused stem bodies before eventual rupture and completion of cytokinesis. (Uranyl acetate and lead citrate; original magnification $\times 14,490$.)

Restored leaflets (group 3), however, which possessed a repopulated interstitium, showed greatly enhanced binding of the antivimentin monoclonal antibody and reinstatement of an even distribution.

Binding patterns of $\alpha$-smooth muscle actin were also altered with each experimental interval (Fig 9). A pattern of a gradual reduction in binding continued through the successive intervals. In the 24-hour group

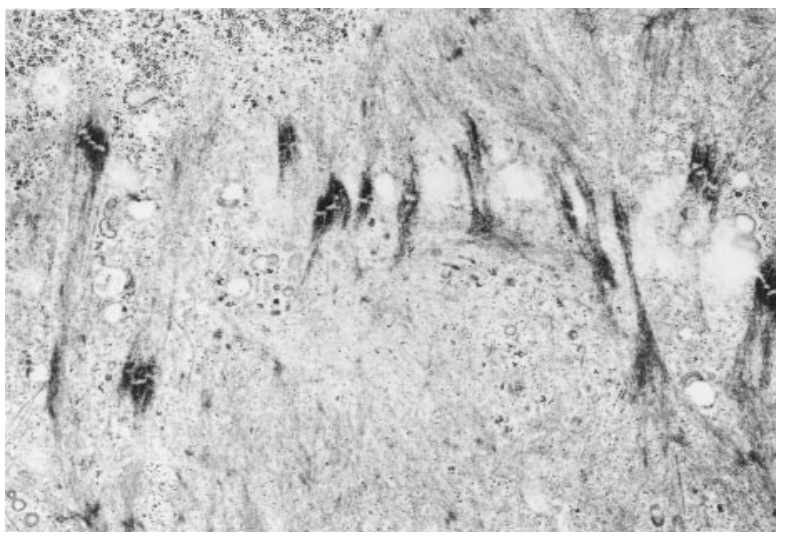

Fig 7. Transmission electron micrograph of 24-hour group 3 leaflet showing well-elaborated intercellular desmosomelike junctional complexes. Inserting microfilaments possess electron-dense bodies. (Uranyl acetate and lead citrate; original magnification $\times 14,490$.)

2 leaflets immunofluorescence was undetectable. After resuscitation the labeling returned to a high-intensity distribution in the lamina ventricularis, with scattered localization in the deeper leaflet segments. Occasional focal areas of hyperplasia with strongly positively staining cells were noted throughout the leaflet.

Monoclonal antibody labeling of chondroitin sulfate in leaflet segments indicated that marked changes occurred during processing. In the 2-hour group 1 leaflets chondroitin sulfate was homogeneously stained. After 22 additional hours of ischemia (24-hour group 1), binding was nearly ablated, reflecting a dissolution of much of the soluble matrix. With subsequent processing the anti-chondroitin sulfate binding was undetectable. With resuscitation binding patterns were similar to those seen in the 2-hour group 1 leaflets.

Fibronectin was present in leaflets through all experimental intervals (Fig 10). In the 2 hours of preharvest ischemia-only valves (2-hour group 1 ), fibronectin was localized to the aortic leaflet interstitial cells throughout the leaflet. Decreases in binding were noted with successive experimental intervals. The 2-hour group 1 leaflets did possess more fibronectin, but the immunofluorescence remained strong even in the maximally processed 24-hour group 2 leaflets. After resuscitation (2- and 24-hour group 3) an increased binding indicative of nascent fibronectin synthesis was evident.

Cell contraction. A baseline tonus was evident among cells released from the 2-hour group 1 leaflets within 24 hours of plating on the silicone. These cells readily adhered to the substrate and contracted (or 

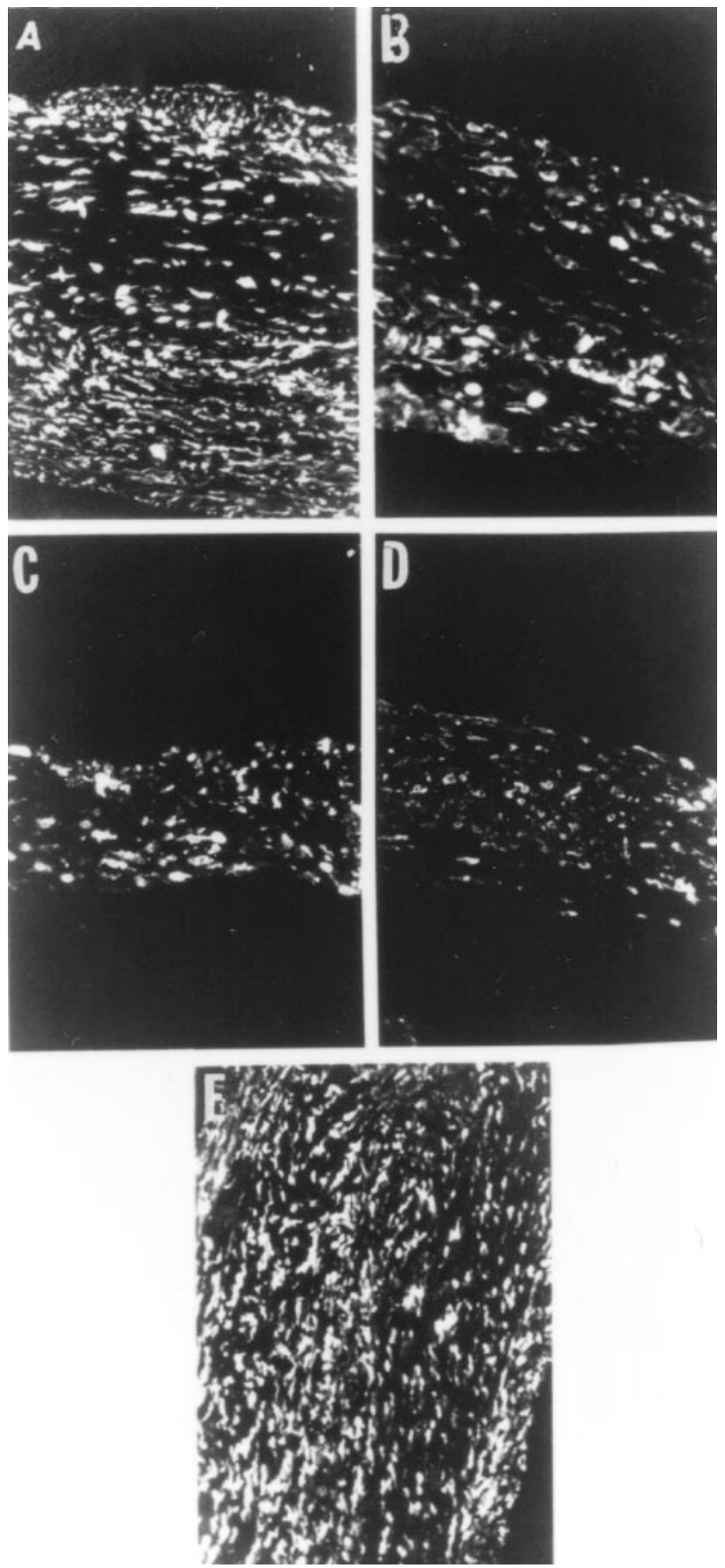

Fig 8. Composite immunofluorescent micrographs depicting localization and pattern of distribution of vimentin in leaflet cross sections throughout ischemia, processing, and resuscitation. A, After 2 hours of preharvest ischemia (2-hour group 1). Relatively even distribution of vimentin is consistent with healthy cellularity in matrix. (Original magnification $\times 400$.) B, 24-hour group 1 leaflet indicating patchy distribution within interstitium itself. Even among single cells binding is variable. (Original magnification $\times 400$.) $\mathbf{C}, 2$ hours of preharvest ischemia and completed processing result in pattern similar to that observed in 24-hour group 2 leaflets. (Original magnification $\times 400$.) D, 24-hour group 2 leaflets show markedly reduced labeling of antivimentin monoclonal antibody. (Original magnification $\times 400$.) E, After 24 hours of preharvest ischemia, completed processing, and resuscitation. Vimentin is readily apparent among newly populated cells distributed evenly throughout leaflet. (Original magnification $\times 400$.) 

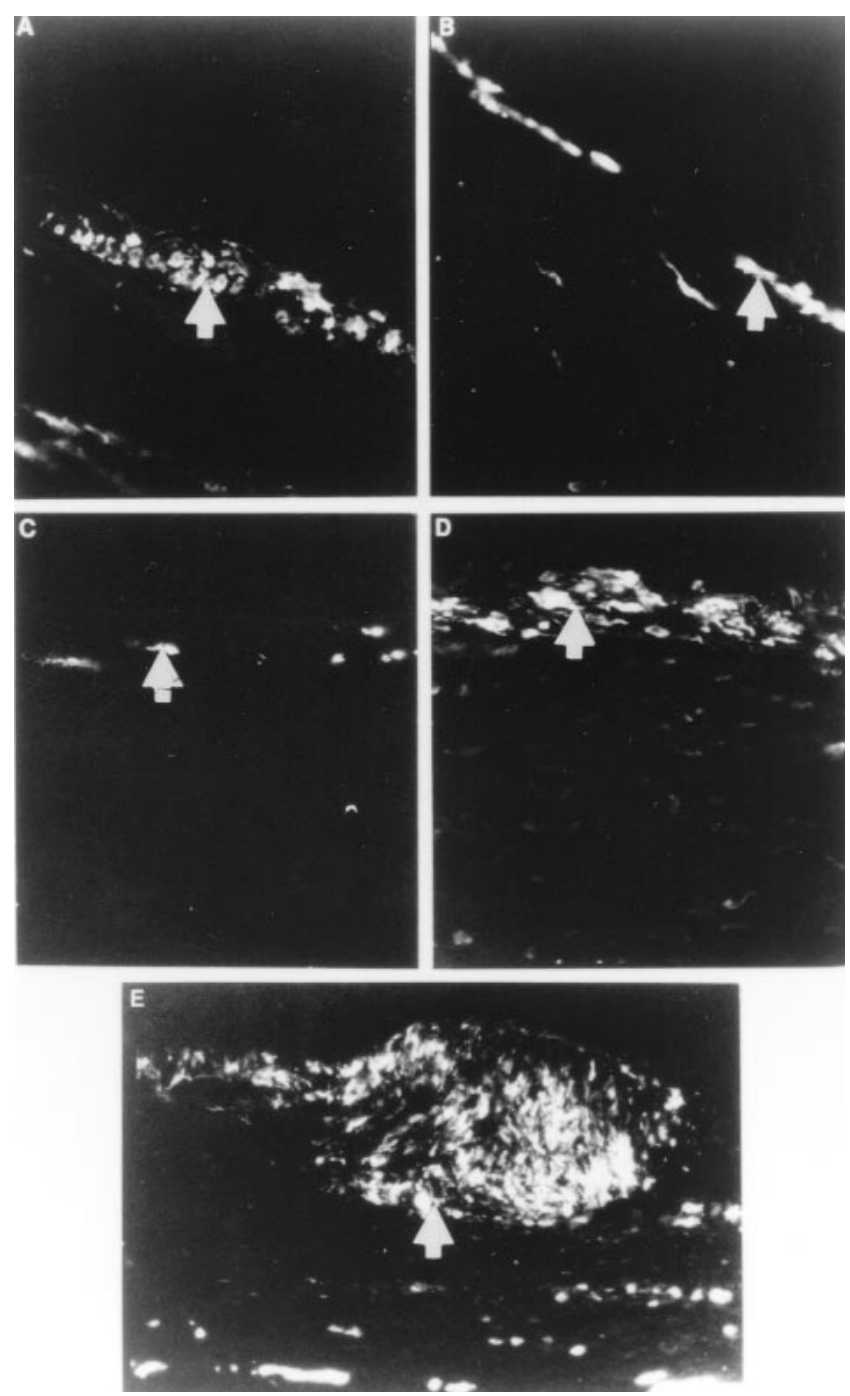

Fig 9. Composite immunofluorescent micrographs showing $\alpha$-smooth muscle actin distribution throughout experimental intervals. Arrows indicate region of lamina ventricularis. A, After 2 hours of preharvest ischemia. (Original magnification $\times 400$.) $\mathbf{B}$, After 24 hours of preharvest ischemia. (Original magnification $\times 400$.) $\mathbf{C}$, After 2 hours of preharvest ischemia and processing (2-hour group 2). This minimal labeling of scattered individual cells was undetectable in 24-hour group 2 leaflets. (Original magnification $\times 400$.) D and E, Resuscitated leaflets repopulated with interstitial cells demonstrate avid positive binding. Note region of hypercellularity in lamina ventricularis shown in E. (Original magnification $\times 400$.)

relaxed) after administration of each drug. In each of the succeeding groups, however, including the 24-hour group 1 leaflets, attachment of cells to the silicone substratum was unstable. Initial cellular spreading could be appreciated within 6 to 12 hours, and the cells appeared morphologically normal. However, many cells would rapidly lift from the rubber either spontaneously or with application of the drugs, if this was attempted within 24 hours of plating. Therefore the experiment was performed on 24-hour group 1 and all group 2 and 3 leaflets after a more prolonged plating period (72 hours). No losses of the contractile and relaxive responses were observed during the various processing intervals. When allowed a sufficient recovery, cells from all leaflet digestates (24-hour group 1, 2- and 24-hour group 2, and 2- and 24-hour group 3) responded similarly. Angiotensin II, epinephrine, carbachol, potassium chloride, and bradykinin caused a brisk evolution of wrinkles, whereas isoproterenol consistently relaxed the cells (Fig 11). 


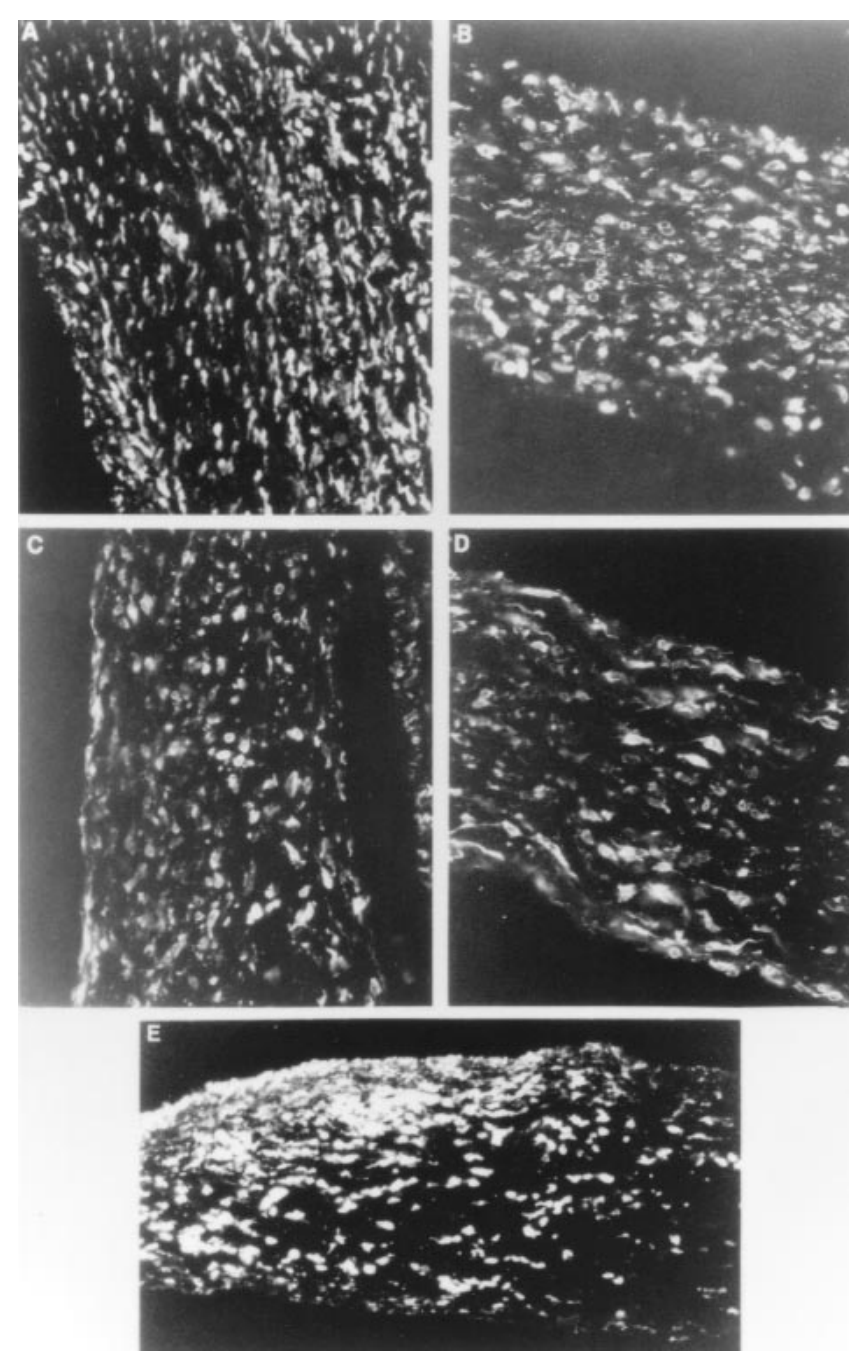

Fig 10. Composite immunofluorescent micrographs showing the distribution of cellular fibronectin during experimental intervals. A, After 2 hours of preharvest ischemia. Fibronectin is in close association with aortic leaflet interstitial cells and therefore distributed throughout leaflet. (Original magnification $\times 400$.) B, After 24 hours of preharvest ischemia. Fibronectin is well maintained. (Original magnification $\times 400$.) $\mathbf{C}$, After 2 hours of preharvest ischemia and processing. Moderate reduction in antifibronectin binding is evident. (Original magnification $\times 400$.) D, After 24 hours of preharvest ischemia and processing. Decreased binding from previous intervals is appreciable. (Original magnification $\times 400$.) E, Restored leaflet. Consistent with repopulated interstitium, newly synthesized fibronectin is apparent. (Original magnification $\times 400$.)

\section{Discussion}

Aortic valve durability has been argued to depend in part on the function of fibroblastic matrix cells within the leaflet interstitium. ${ }^{2-6}$ In the native state this population has been shown to synthesize extracellular leaflet matrix proteins in response to specific stressstrain stimuli, probably contributing to the remarkable durability of undiseased valve leaflets. ${ }^{4}$ Accordingly, the objectives of human valve cryopreservation have been not only to store and subsequently implant a hydraulically favorable prosthesis but also to transplant capacity for growth, repair, and remodeling through the gentle preservation of donor cell viability. The biophysics and cellular physiology of cryogenic storage have been well studied in many tissues and single-cell suspensions ${ }^{22}$; however, extrapolation from data derived from single-cell preparations cannot be applied to cardiac valve leaflets, in part because 3dimensional structures do not generally sustain the requisite uniform tissue freeze necessary for maxi- 

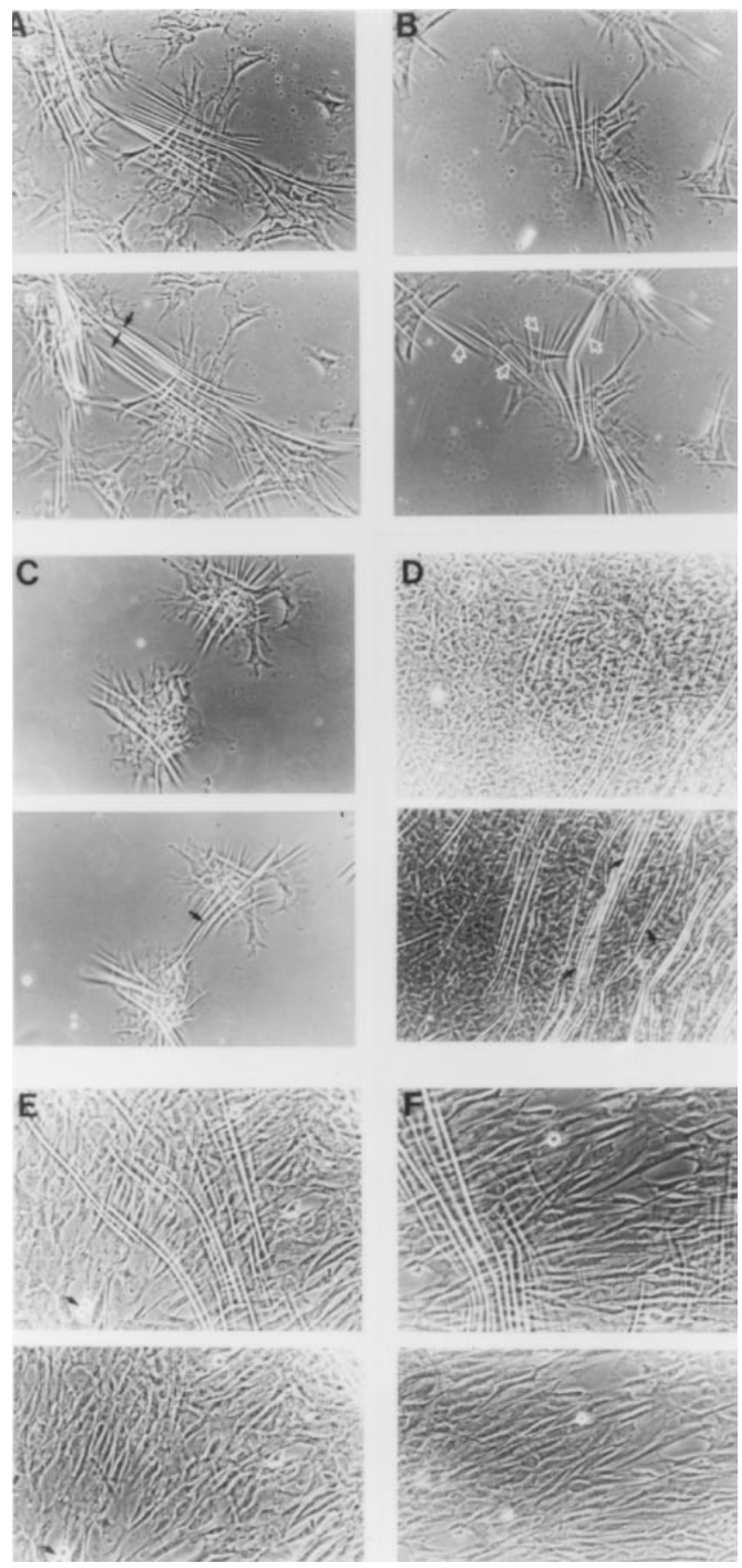

Fig 11. Composite phase-contrast micrographs of cells plated from leaflets at various ischemic, processing, and restoration phases. Cells were released by collagenase digestion at each interval and grown on flame-polymerized silicone rubber. Photographs were taken before (top plates) and after (bottom plates) each physiologic challenge. A, Response to $320 \mathrm{nmol} / \mathrm{L}$ angiotensin II in interstitial cells released from aortic leaflets after 2 hours of preharvest ischemia only. Arrows indicate developing contractile wrinkles. B, Response to $110 \mu \mathrm{mol} / \mathrm{L}$ carbachol in interstitial cells released from aortic leaflets after 24 hours of preharvest ischemia only. Open arrows indicate contractile wrinkles. C, Response to $100 \mathrm{nmol} / \mathrm{L}$ epinephrine in interstitial cells released from aortic leaflets sustaining 2 hours of preharvest ischemia followed by disinfection and cryopreservation. Arrows depict developing wrinkles. D, Response to $300 \mathrm{nmol} / \mathrm{L}$ bradykinin in interstitial cells released from aortic leaflets sustaining 24 hours of preharvest ischemia, disinfection, cryopreservation, and restoration. E, Response to $110 \mu \mathrm{mol} / \mathrm{L}$ isoproterenol in interstitial cells from aortic leaflets sustaining 24 hours of preharvest ischemia, disinfection, and cryopreservation. Wrinkles dissipate rapidly from baseline tonus. Note progression of mitosis (arrows). F, Similar relaxation response to same dose of isoproterenol is seen among cells from leaflets sustaining 24 hours of preharvest ischemia, disinfection, cryopreservation, and restoration. 
mum postthaw viability, despite the use of cryoprotective agents.

In previous studies conducted by our group adenine nucleotide pool components extracted from porcine valve leaflets exposed to staggered intervals of the standard homograft processing and cryopreservation protocol were quantified with high-performance liquid chromatography. ${ }^{8-12,14,15}$ These analyses indicated that a marked energy store depletion took place, particularly during disinfection and cryopreservation itself, and that most cells if not dead were metabolically stunned. ${ }^{11}$ Although protein losses were also noted during processing, there are few data regarding the fates of specific protein components. These studies also showed that despite marked high-energy phosphate depletion small quantities of energy stores were measurable as a nucleotide reserve, indicative of a resilient subset of leaflet interstitial cells that were present in even fully processed porcine leaflets sustaining the maximum 24 hours of preharvest ischemia. ${ }^{8-13} \mathrm{We}$ also found a similar subgroup within the stunned leaflet myofibroblast population in human cryopreserved valves. ${ }^{11}$ Our current results suggest that only a small population of such retained hardy cells may be required as an inoculum on which to base restoration of interstitial cell populations.

The interstitial cells of mitral valve leaflets have been characterized by several groups to possess features similar to smooth muscle cells. ${ }^{23,24}$ Our laboratory was the first to demonstrate that interstitial cells from semilunar valves were also rich in smooth muscle-specific $\alpha$ actin, vimentin, and were able to secrete both fibronectin and chondroitin sulfate. These cells are capable of contractile and relaxive responses when challenged with physiologic stimuli, as manifested by wrinkle formation when plated on flame-polymerized silicone $^{18,25}$ (that is, they are myofibroblasts).

In this study we followed changes in these identifying characteristics through the intervals of ischemia and processing and then attempted a restitution to the "native" state by means of a period of organ culture that we termed resuscitation. Resuscitation was essentially cellular bioengineering after thaw through mitotic stimulation of the residual population that had survived processing. FBS at $15 \%$ concentration has been demonstrated in our laboratory to be the most efficient additive for these cells when compared with individual cytokines such as endothelium-derived relaxing factor and platelet-derived growth factor. ${ }^{12}$ Presumably this is due to the combination of various growth factors (known and unknown) present in FBS as opposed to single additives. Thus although data from our own series of studies as well as other laboratories suggest that only a few viable and functioning interstitial cells survive through transplantation, this study demonstrated that the reduction in population of living healthy cells, as well as any depletion of matrix proteins in the interstitium, could be reversed by in vitro cellular engineering to generate a more densely populated and functional leaflet before transplantation.

This study does not address the issue of whether such restored but genetically unmodified donor cell populations remain functional for a prolonged period after transplantation. It is possible that although cellular elements are beneficial initially in restoring leaflet functional properties they may render the valve more antigenic, ultimately resulting in greater rejection and inflammatory responses by the host and thus reducing durability, as has been suggested in neonatal recipients. These results suggest the feasibility of the alternate and appealing strategy of repopulating with immunologically compatible or genetically altered cells.

As a first step we used the standard viability assay of trypan blue dye exclusion, an indicator of functional plasma membrane integrity. ${ }^{26}$ The trypan blue test by itself is not a perfect viability assay because it cannot predict future viability or indicate origin and mitotic potential of cells, and it may be susceptible to denominator errors. Nevertheless, it is a routinely used assay in cell culture laboratories for comparison of cell viability between comparably managed cell cultures. Other types of cell labeling techniques (eg, bromodeoxyuridine and genetic markers) have additional advantages and would be mandatory for long-term implant studies. Viable cell numbers do not appear to change significantly in the clinical harvest period between 2 and 24 hours post mortem. After processing, and without relationship to preharvest ischemia, viable cell density always falls precipitously. We therefore believe that the agreement between simple, visual viability assays (trypan blue), quantitative electron microscopy, and sensitive, precise metabolic analyses (high-pressure liquid chromatography) demonstrates fairly conclusively that the cellular population decreases during preimplantation processing. ${ }^{9,11}$

On ultrastructural examination, leaflets that had been ischemic for 24 hours showed overt subcellular changes despite continued ability to exclude trypan blue. ${ }^{26,27} \mathrm{We}$ have also noted similar effects on human leaflet cells in cryopreserved specimens harvested after varying durations of ischemia and that such changes appeared to evolve in a time-dependent manner. ${ }^{16}$ Conversely, plasma membranes themselves were often intact, perhaps attesting to the means by which the cells continued to exclude the vital dye at 24 hours. In addition, these responses seen with the electron microscope serve to emphasize the difficulties of real-time viability assays. 
Cells may show no evidence of damage by a given indicator, whereas damage is overt according to another.

We suspect that the near ablation of chondroitin sulfate through 24 hours of ischemia is probably due to simple leeching and should be expected to occur during any interval of valve suspension. At present, all donor valves in the United States are subjected to hypothermic and prolonged immersion in an antibiotic solution.

The group 2 leaflets were specifically designed to examine the matrix and cells shortly after thawing. Clinically this is a time when certain measures could be performed in the operating room to ensure minimal osmolysis and rapid rewarming. Theoretically these precautions are prudent because transient cell dysfunction and osmotic fragility have been noted in many cell types to be characteristic of the thaw interval. ${ }^{15,28,29}$ In the situation of valve cryopreservation, our studies indicate not only that this dysfunction is a consideration but also that there is a severe reduction in potentially viable cells. The reductions in monoclonal antibody binding to the contractile intracellular $\alpha$-smooth muscle actin and the intermediate filament vimentin, as well as to pericellular fibronectin, were in agreement with our viability assessments at each stage. We therefore conclude that current cardiac cryopreserved homografts possess a markedly altered interstitium with a reduced and compromised cell population and a matrix that has been stripped of many soluble components. In even the most rigorously stressed valves (24-hour group 2), however, some cells remain that could be considered "normal" by several parameters. This occasional instance of morphologic integrity was accompanied by retained functional abilities. Collagenase digestates of both 2- and 24-hour group 2 leaflets demonstrated mitosis to be a spared process. The specialized cellular function of contraction was not obviated through processing. In collagenase digestates of leaflets from each group, cells retained a baseline tonus and could still be induced to contract or relax in response to challenge.

In this study we reasoned that perhaps the small subset of viable and functional leaflet interstitial cells could be stimulated to repopulate the virtually barren collagen lattice of a cryopreserved valve leaflet. This hypothesis was tested with the resuscitated leaflets of group 3. A complete restoration of the numeric population was shown to be achievable during a period of 8 days with simple organ culture in $15 \%$ FBS. The rate of this repopulation may be appreciated by examining Fig 2 , in which weighed leaflets were digested in collagenase each day and the cells were counted. The growth curve was similar in morphologic appearance to that seen in leaflet interstitial cells in culture with $15 \%$ FBS.

In any organ culture setting the possibility of a purely fibroblastic overgrowth must be ruled out. By using the ultrastructural features, protein identification, and verification of contractile responses to physiologic agents we were able to characterize the restored population as phenotypically similar to the original population. The group 3 leaflets were not simply segments of collagen repopulated with standard connective tissue fibroblasts. They were restored and functional semilunar cusps that showed evidence of a normal matrix. The cells retained synthetic capabilities, contractile function, and mitotic potential, and they could be anticipated to be capable of growth, repair, and remodeling. Whether these potential activities would continue to be expressed after transplantation will require validation by long-term implant studies.

The function of these interstitial myofibroblast cells in vivo remains undefined. We and others have previously speculated on an interaction between contractile properties and the synthesis of extracellular matrix in an environment of varying hemodynamic stresses and have conjectured that this may be central to the remarkable durability of native aortic valves. ${ }^{12,30}$ These studies show that this specific interstitial cell population in cryopreserved leaflets may be restored in vitro after thaw. Such techniques may be extrapolated to other seeding strategies as well as to donor cell restoration.

\section{REFERENCES}

1. Hopkins RA. Right ventricular outflow tract reconstructions. In: Hopkins RA. Cardiac reconstructions with allograft valves. New York: Springer-Verlag; 1989. p. 155-87.

2. Hopkins RA. Historical development of the use of homograft valves. In: Hopkins RA. Cardiac reconstructions with allograft valves. New York: Springer-Verlag; 1989. p. 3-13.

3. O'Brien MF, Stafford EG, Gardner MA, Pohlner PG, McGiffen DC. A comparison of aortic valve replacement with viable cryopreserved and fresh allograft valves, with a note on chromosomal studies. J Thorac Cardiovasc Surg 1987;94:812-23.

4. Thubrikar MJ, Nolan SP, Aouad J, Deck JD. Stress sharing between the sinus and leaflets of canine aortic valve. Ann Thorac Surg 1986;42:434-40.

5. Anderson $\mathrm{AB}$. A notebook for the human heart valve patient. Marietta [GA]: CryoLife; 1985. p. 1-7.

6. Hopkins RA, Messier RH Jr, Domkowski PW. Homograft valve transplants. In: Flye MW, editor. Atlas of organ transplantation. Philadelphia: WB Saunders; 1993. p. 331-47.

7. Lange PL, Hopkins RA. Allograft valve banking: techniques and technology. In: Hopkins RA. Cardiac reconstructions with allograft valves. New York: Springer-Verlag; 1989. p. 37-64.

8. Messier RH Jr, Domkowski PW, Aly HM, Abd-Elfattah AS, Crescenzo DG, Wallace RB, et al. High energy phosphate deple- 
tion in leaflet matrix cells during processing of cryopreserved cardiac valves. J Surg Res 1992;52:483-8.

9. Domkowski PW, Messier RH Jr, Crescenzo DG, Aly HS, AbdElfattah AS, Hilbert SL, et al. Preimplantation alteration of adenine nucleotides in cryopreserved heart valves. Ann Thorac Surg 1993;55:413-9.

10. Abd-Elfattah AS, Messier RH Jr, Domkowski PW, Jones JL, Aly $\mathrm{HM}$, Crescenzo DG, et al. Inhibition of adenosine deaminase and nucleoside transport: utility in a model of homograft cardiac valve preimplantation processing. J Thorac Cardiovasc Surg 1993;105:1095-105.

11. Messier RH Jr, Domkowski PW, Aly HM, Jones JL, Hilbert SL, Crescenzo DG, et al. Adenine nucleotide depletion in cryopreserved human cardiac valves: the "stunned" leaflet interstitial cell population. Cryobiology 1995;32:199-208.

12. Messier R. The cardiac valve allograft: restoration of aortic leaflet interstitial cellular function following alterations mediated by cryobiologic processing [dissertation]. Georgetown University, Washington DC, July 6, 1993. Ann Arbor (MI): UMI Dissertation Services; 1995. p. 1-385.

13. Messier RH Jr, Bass BL, Aly HM, Jones JL, Domkowski PW, Wallace RB, et al. Dual structural and functional phenotypes of the porcine aortic valve interstitial population: characteristics of the leaflet myofibroblast. J Surg Res 1994;57:1-21.

14. Messier Jr RH, Domkowski PW, Abd-Elfattah AS, Aly HM, Crescenzo DG, Analouei AR, et al. Analysis of the total adenine nucleotide pool in 25 cryopreserved human cardiac valves [abstract]. Circulation 1991;84(Suppl):II640.

15. Kawamoto JC, Barrett JN. Cryopreservation of primary neurons for tissue culture. Brain Res 1986;384:84-93.

16. Crescenzo DG, Hilbert SL, Barrick MK, Corcoran PC, St Louis JD, Messier RH, et al. Donor heart valves: electron microscopic and morphometric assessment of cellular injury induced by warm ischemia. J Thorac Cardiovasc Surg 1992;103:253-7.

17. Harris AK, Wild P, Stopak D. Silicone rubber substrata; a new wrinkle in the study of cell locomotion. Science 1980;208:177-9.
18. Morel NM, Dodge AB, Patton WF, Herman IM, Hechtman HB, Shepro D. Pulmonary microvascular endothelial cell contractility on silicone rubber substrate. J Cell Physiol 1989;141:653-9.

19. Chamley JH, Gröschel-Stewart U, Campbell GR, Burnstock G. Distinction between smooth muscle, fibroblasts, and endothelial cells in culture by the use of fluoresceinated antibodies against smooth muscle actin. Cell Tiss Res 1977;177:445-57.

20. Reynolds ES. The use of lead citrate at high $\mathrm{pH}$ as an electronopaque stain in electron microscopy. J Cell Biol 1963;17:208-13.

21. Bairati A, DeBiasi S. Presence of a smooth muscle system in aortic valve leaflets. Anat Embryol 1981;161:329-40.

22. Mazur P, Cole KW, Hall JW, Schreuders PD, Mahowald AP. Cryobiological preservation of Drosophila embryos. Science 1992;258:1932-5.

23. Filip DA, Radu A, Simionescu M. Interstitial cells of the heart valves possess characteristics similar to smooth muscle cells. Circ Res 1986;59:310-20.

24. Lester W, Rosenthal A, Granton B, Gotlieb A. Porcine mitral valve interstitial cells in culture. Lab Invest 1988;59:710-9.

25. Burridge K. Are stress fibers contractile? Nature 1981;294:691-2.

26. Frim J, Mazur P. Interaction of cooling rate, warming rate, glycerol concentration and dilution procedure on the viability of frozen-thawed human granulocytes. Cryobiology 1983;10:657-76.

27. Leibo SP, Farrant J, Mazur P, Hanna Jr MD, Smith LH. Effects of freezing on marrow stem cell suspensions: interactions of cooling and warming rates in the presence of PVP, sucrose, or glycerol. Cryobiology 1970;6:315-32.

28. De Loecker R, Goossens W, Bruneel P, Van Duppen V, Penninckx F, Verwilghen $R$. The prevention of erythrocyte swelling upon dilution after freezing and thawing. Cryobiology 1991;28:237-45.

29. Dou M, de Sousa G, Lacarelle B, Placidi M, Lechene de la Porte $\mathrm{P}$, Domingo M, et al. Thawed human hepatocytes in primary culture. Cryobiology 1992;29:454-69.

30. Deck JD. Histology and cytology of the aortic valve. In: Thubrikar M. The aortic valve. Boca Raton [FL]: CRC Press; 1991. p. 21-38. 